\title{
La ciudad híbrida \\ La mediación de las TIC en la experiencia de la ciudad
}

\author{
Hybrid city. \\ Mediation of ICT in the city experience
}

\author{
Angelique Trachana \\ Escuela Técnica Superior de Arquitectura. Universidad Politécnica de Madrid \\ 9737trachana@coam.es
}

Recibido: 24 de enero de 2013

Aprobado: 2 de diciembre de 2013

\section{Resumen}

El concepto de "ciudad híbrida" se acuña en el nuevo contexto tecnológico para señalar una serie de fenómenos contemporáneos que se producen en la conjunción de las condiciones físicas de la ciudad y la virtualidad de soporte tecnológico. El término puede encontrase asociado a categorías tan actuales como smart cities o "ciudades inteligentes", "ciudades de código abierto" y a los nuevos "aprendizajes" de "hacer ciudad" con el "uso cotidiano de internet". Aquí, sin embargo pretendemos extender el alcance de su significado haciendo una síntesis de "aprendizajes" que modifican nuestra percepción del entorno. Desde el mundo de las artes como la fotografía o el cine hasta la televisión y ahora internet y las múltiples herramientas telemáticas de uso cotidiano, comprobamos cómo la mediación tecnológica, incide intensificando la percepción sensible de la ciudad y ampliando el imaginario de los ciudadanos. En consecuencia se están fundando nuevos hábitos en la vida ciudadana y experimentando nuevos modelos de gestión de la ciudad. La identidad híbrida, presencial y digital, es un hecho, un género de espacio nuevo que integra el potencial imaginario y virtual que propicia la tecnología digital en el espacio físico. En estos espacios -que se generan en la red y se verifican in situ- se despliegan dinámicas interactivas y emerge la creatividad ciudadana; frecuentemente constituyen la parte informal de la ciudad.

Palabras clave: ciudad, arte, TIC, ciudadanía proactiva.

Trachana, A. (2014): La ciudad híbrida. La mediación de las TIC en la experiencia de la ciudad. Arte, Individuo y Sociedad, 26 (2) 233-254.

\begin{abstract}
The concept of "hybrid city" is being built in the new technological context to indicate a range of contemporary phenomena that occur at the junction of the physical conditions of the city and the virtuality of technological support. The term can be found associated with current categories such as "smart cities" or "open source cities" and new "learning" to "make city" by means of "the everyday use of Internet." Here however we aim to extend the scope of its meaning by making a synthesis of different ways of "learning" that change our perception of the environment. From the world of art as photography and cinema to television and now the internet and the daily use of many online tools, we see how technological mediation affects enhancing sensory perception of the city and expanding the citizens' imagination. Consequently new habits in civic life are being founded and new models of city manage-
\end{abstract}


ment are taking place. The hybrid identity of space between the presential and digital reality is, in fact, a kind of new space that integrates the virtual imaginary potential facilitated by digital technology in the physical space. In these spaces, which are generated in the network and developed in situ, interactive dynamics are being deployed helping develop citizens's creativity. They often constitute the informal part of the city

Keywords: city, art, ICT, proactive citizenship.

Trachana, A. (2014) Hybrid city. Mediaton of ITC in the city experience. Arte, Individuo y Sociedad, 26 (2) 233-254.

Sumario: 1. Entre la experiencia naturalista de lo urbano y el espacio virtual, 2. El arte y lo real, 3. Tecnología y ciudadanía proactiva. Referencias.

Este trabajo deriva del Proyecto de Investigación ‘Atlas Interactivo de habitabilidad urbana' financiado por el MICINN - Plan Nacional I+D+I+i - 2011.

\section{Entre la experiencia naturalista de lo urbano y el espacio virtual}

Asistimos hoy a una nueva alfabetización del espacio basada en una percepción más sensible, aumentada e intensificada por los medios tecnológicos de utilización generalizada. La abundancia de información, de estímulos que recaen sobre nuestros sentidos y la aceleración del tiempo por la mediatización informática de los procesos que jalonan nuestra vida cotidiana, están produciendo una transformación de nuestra percepción del mundo, un cambio radical de nuestras conciencias. El individuo conectado que aprende a utilizar esos medios para innovar y personalizar su modo de vida, está empezando, como una práctica habitual, a describir y compartir la experiencia de su entorno pasando de ser agente pasivo a elemento activo de este entorno. Las anotaciones individuales sobre lo cotidiano añaden nuevas capas de significado al territorio en cuanto escenario del habitar y convivir, elaborando narrativas dinámicas y simultáneas que adquieren un enorme poder de construcción social y se configuran como herramientas educativas del ciudadano que está descubriendo en las tecnologías descentralizadas una fantástica herramienta de participación y lucha por un mundo mejor.

Siempre el ser humano ha utilizado las herramientas que tuvo a su alcance en cada momento para describir el mundo y para comprender lo que le rodea. Cada civilización, cada nuevo hallazgo técnico sugiere inmediatamente una mirada nueva. Cada mirada nueva propicia a su vez nuevos hallazgos. Esa estricta correspondencia ha movido el mundo. Las TIC nos permiten hoy nuevos aprendizajes, nuevas formas de organización y de estar en el mundo. Organizaciones más horizontales frente a las estructuras autoritarias se propician en las redes. Las redes sociales de soporte tecnológico constituyen hoy nuevos sistemas de comunicación e interacción donde se detectan nuevas problemáticas y se organizan diferentes sensibilidades en colectivos activos y efectivos en producir cambios. Visiones subjetivas de los ciudadanos sobre infinidad de acontecimientos, configuraciones instantáneas, contingentes de un medio cambiante, se describen, se difunden y se comparten en la red constituyendo un caudal de información invertebrada pero contribuyendo en una sensibilización por el 
entorno. Redes sociales se organizan en torno a propuestas, opciones y reivindicaciones que tienen como epicentro la vida urbana localizada o dislocada.

Los medios locativos nos permiten leer y escribir mientras nos desplazamos facilitando un conocimiento compartido, posible gracias a múltiples aplicaciones disponibles de forma gratuita. El uso de herramientas de georreferenciación se extiende a todo tipo de prácticas culturales y sociales. La integración de las tecnologías emergentes en la creación y difusión de contenidos digitales enriquecen, sin duda, la precepción de cada territorio potenciando el diálogo entre espacio y memoria, haciendo aparecer lo oculto desconocido de cada lugar. Una participación constructiva y transformativa del entorno es posible gracias a la manipulación creativa de la información, lo que convierte a uno en autor o coautor de nuevos relatos.

Esta percepción "activa" del "entorno complejo y cambiante" difiere completamente de aquella visión moderna, tecnocrática y utópica que concebía y describía el espacio como geometría a través de planos con toda claridad: espacio abstracto, cartesiano, puro, inequívoco. Los arquitectos modernos concebían la ciudad como una tabula rasa donde los objetos se ordenaban a partir de la determinación de sus volúmenes nítidos y su relación visual. La ciudad antigua, asentada sobre el suelo natural, había ido allanándose, igualándose sus bordes y preparándose para levantar sobre él estructuras materiales indiferentes al entorno, siguiendo los proyectos ideales de una mente humana liberada de las cadenas del pasado. La ciudad de los edificios es una concepción abstracta de orden visual, ajena a la vida y fundada en la estética y la técnica, que emana de una "idea" platónica. La producción de este modelo de espacio urbano ordenado, racionalizado, y jerarquizado, no corresponde a la vida real de la ciudad que en sí se desenvuelve como anarquía y caos.

Hoy, sin embargo, desde distintas disciplinas se indaga en la caótica consistencia de la vida urbana. La visión de la ciudad como vida urbana se suscita primero en el arte y muy particularmente en la narrativa. Las ciencias humanas que estudian lo urbano como la sociología, ha acercado sus métodos de análisis e interpretación a la antropología y la etnología. En el urbanismo empiezan a incorporarse importantes cambios procedimentales de intervención urbana que derivan de la psicología, la ecología, el paisaje y la participación ciudadana. Se exploran modelos diferentes de la identificación de los fragmentos urbanos con funciones urbanas, modelos opuestos a la concepción del "paisaje" urbano como taxonomía social. Una tendencia hacia la "experiencia naturalista" del espacio suplanta la voluntad obsesiva de orden visual otorgando sentido al amorfo y variable tejido urbano. Se le otorga valor positivo al imperceptible orden del tejido urbano por la heterogeneidad y la riqueza social que contiene, por las relaciones que propicia, relaciones imprevistas, casuales, potenciales.

En arquitectura los profesionales más jóvenes e inteligentes están explorando propuestas más naturales introduciendo principios éticos y estéticos que incluyen reducción de costes y principios de sostenibilidad frente a las estrategias proyectuales dirigidas exclusivamente a la forma/diseño. Frente a una relación simbólica con el espacio, que fomenta la ciudad tradicional, hay un giro hacia la experiencia sensitiva del espacio. La descripción de las propiedades palpables de nuestro entorno y la implicación del cuerpo directamente en la producción de espacio, constituyen 
claves importantes del discurso arquitectónico. En la enseñanza de la arquitectura se investiga acerca de mecanismos de configuración -desde el dibujar- diferentes de la producción de imágenes (Trachana, 2012a, 288-297).

Esa no es una visión nueva sino inevitablemente influenciada por autores como Baudelaire (1863), Georg Simmel (1903), Walter Benjamin (1938), Guy Debord (1957), Constant (1974), Henri Lefebvre (1978), Richard Sennett (1997), Michel de Certeau (1999), Paul Ricoeur (2000), Pascal Nicolas-Le Strat (2006), Zygmunt Bauman (2007), Manuel Delgado (2007), Antonio Negri (2010). Esa mirada se vincula a las figuras ambiguas del flâneur o del "jugador" de Baudelaire, a ese paseante urbano en los "retratos de ciudades" de Benjamin elevado a la categoría de héroe y guía. Como un arqueólogo que indaga en las ruinas de una civilización futura, un detective multifacético al que afecta aquello que investiga, observador y observado, comprador y mercancía, actor y espectador, en palabras de C. Rendueles y A. Useros (2010), este héroe urbano trata de explicar las contradicciones de los procesos de modernización. Es la visión que recupera la psicogeografía situacionista (Debord, 1957) y el nómada babilónico del Contant (1974). Ésta se identifica con la visión del artista urbano y el ciudadano pro-activo y creativo, "que lejos de permanecer pasivo ante un mundo donde se contenta con adaptarse, de una manera o de otra, a las circunstancias externas, puede imaginar su vida, eso es, crearla y recrearla" (Trachana, 2013 a , 52).

Bajo esta mirada, la ciudad ya no se puede entender como su estable, monumental y representativa imagen mítica; la ciudad planificada y edificada por los arquitectos. Es "lo urbano lo que genera la ciudad", lo urbano entendido como un continuo fluir que no puede cuajar. Lo urbano como prácticas, "la obra perpetua de los habitantes móviles y movilizados por y para esa obra" (Lefebvre, 1972, 70). El espacio urbano es "el espacio que genera y donde se genera la vida urbana como experiencia masiva de la dislocación y el extrañamiento, en el doble sentido de desconocimiento mutuo y de los resortes siempre activados de la perplejidad y la estupefacción" (Delgado, 2007,12 ). La ciudad practicada frente a la ciudad concebida. El ciudadano movilizado por un uso más intensivo del espacio urbano. Esa es la óptica de M. de Certeau $(1999,108)$ y su crítica a Foucault $(1967 ; 1998)$, respecto a las prácticas cotidianas que escapan del control "panóptico": prácticas, algunas de las cuales no tienen siquiera su propio espacio, están continuamente en movimiento y sólo pueden tener su propio tiempo.

Esta lectura corresponde con aquella de los espacios que permanecen fuera de las bolsas de la regulación, los espacios de indeterminada significación que llamaría Solá Morales (2002) terrain vague, los espacios donde tienen lugar la vida cotidiana, las acciones espontáneas y "los accidentes" que transforman continuamente el espacio urbano. Los accidentes imprevistos que producen extrañamiento en los "umbrales" (benjaminianos) de la experiencia y la memoria individual o colectiva son estas "encrucijadas" de potenciales cambios de rumbo, de caminos alternativos. Los cambios en nuestra vida individual o vida común son los que más nos inquietan y nos sacuden. Benjamín en su escritura abrió "umbrales" de un pensamiento complejo de múltiples ramificaciones en el continuo de los mitos dominantes con invenciones de imágenes mentales nodales o con la destrucción y reconstrucción del pensamiento a partir de los escombros. En los "retratos" de las ciudades, la ciudad se presenta como una cris- 
talización material de una forma de vida social donde cada vida individual deja sus particulares huellas. Según Buck-Morss (1989), Benjamin entiende la fisionomía de la ciudad como recuperación intelectual de la experiencia vivencial. La estructura de la experiencia de la ciudad es la travesía. Las ciudades se reconstruyen de fragmentos, de discontinuidades, de descripciones que pretenden estabilizar aspectos que se deterioran en el flujo de la narración mítica y se rearticulan como "constelaciones" nuevas y abiertas. Los aspectos seleccionados en las descripciones de Benjamin son nudos de la experiencia, de la articulación del espacio y el tiempo.

$\mathrm{El}$ arte, sin duda, desde la literatura a las artes visuales, ha sido motor del cambio de la percepción. Según Perniola (2002, 41), el arte hoy irrumpe en lo real. Las barreras entre el arte y la vida se diluyen. El arte se ha apoderado de la calle. Arte urbano, amateurismo cultural y participación activa de los ciudadanos en eventos artísticos y procesos creativos convierten el espacio urbano en escenario de las dramaturgias de la vida urbana. Las nuevas tendencias de configuración del entorno urbano no son exclusivamente arquitectónicas y apuntan hacia una nueva alfabetización del espacio basada en la percepción sensible, en la inducción y la imaginación de los ciudadanos haciendo de las condiciones de nuestro entorno encontrado la base de proyectos imaginativos. Reorganizando y reutilizando creativamente los datos capturados de la realidad y de la vida cotidiana -in situ y virtualmente- se generan nuevas propuestas, nuevos relatos, modos diferentes de experimentar y visualizar la ciudad; se exploran espacios indeterminados creando lugares en el acto de desplazarse, alterando las trayectorias habituales, guiando los viandantes hacia nuevas "derivas" y visualizando nuevas "situaciones". Los ciudadanos actúan habitualmente como intérpretes y gestores de información generada y compartida con medios y herramientas que ellos mismos eligen o diseñan.

La arquitectura ya no es como antaño la única escenificación de la vida urbana. El cine, la televisión, los reportajes de la prensa, las guías de viaje y, sobre todo, las redes sociales telemáticas son los lugares donde se generan los nuevos relatos de la ciudad. El medio virtual no es sólo un medio para representar la realidad sino también para construirla. Según Jonathan Crary (1994), la experiencia psíquica directa de vivir una situación y la tendencia de reflejar esa experiencia a través de un registro permite avanzar hacia una nueva construcción mental definiendo un nuevo individuo cuya percepción del mundo es más productiva, más adaptable y más autónoma sujeto a nuevas funciones de los cuerpos y a una vasta proliferación de signos e imágenes cambiantes. Las experiencias vitales se proyectan como imágenes instantáneas en un espacio virtual -que es muy real- dando visibilidad a los estados afectivos y mnemónicos de los ciudadanos, transeúntes, actores de la escena urbana. Las imágenes generan palabras y las palabras relatos.

Sin los relatos los nuevos barrios quedan desiertos. Por las historias los nuevos lugares se tornan habitables. Habitar es narrativizar. Fomentar o restaurar esa narratividad es, por tanto, una forma de rehabilitación. Hay que despertar a las historias que duermen en las calles (...). Son las llaves de la ciudad (De Certeau, 1999, 128). 


\section{El arte y lo real}

En 1917 un hecho señalado hizo que se derrumbase el arte de su pedestal. Fue cuando Marcel Duchamp envió su famoso urinario de porcelana blanca, firmado con el seudónimo «R. Mutt», a la galería Grand Central de Nueva York para una exposición de artistas independientes (Fig.1). Ese incidente causó un escándalo que sacudió al mundo del arte. Con esta actitud provocadora Marcel Duchamp quiso mostrar su desilusión ante las formas tradicionales del arte -la pintura y la escultura como medios de expresión- y su rechazo ante la idea de que el arte y el artista tienen una «naturaleza especial» distinta a la de las personas y objetos ordinarios. Su gesto de enviar a la exposición un producto comercial fabricado en serie y firmado por un «artista» inexistente, se oponía radicalmente a la sacralización de la obra de arte como «creación única e irrepetible», salida de las manos de un «genio». Este desafío «antiartístico» rompía las barreras del arte y ampliaba sus horizontes. Desde entonces, se otorga al ready-made, o l'objet trouvé, es decir, el objeto común descontextualizado, una nueva identidad donde se ubica la esencia del acto artístico. Eso es, en la selección del objeto, no en la creación ni en la imagen visual de la obra. Esta trasgresión y violencia de Duchamp compartida con los dadaístas buscaba demoler las barreras entre el arte y la vida, declarando que cualquiera podía ser un artista y cualquier cosa podía convertirse en una obra de arte. El arte no está en el objeto sino en la conciencia, en la mirada que se arroja sobre él.

Gordon Matta-Clarck (1972-73) extrae a sierra fragmentos de edificios abandonados de Bronx convirtiéndolos en objetos de exposición y considerando el edificio intervenido como la obra en sí, una obra destinada a desaparecer ya que los edificios intervenidos eran siempre inmuebles a punto de ser demolidos (Fig.1). Con estas obras, pretendía activar la memoria y hacer una lectura positiva de estos residuos urbanos. Al convertir estos fragmentos y estas instalaciones en imágenes -fotografías-, pretendía además demostrar el papel que juega la representación de un espacio en la experiencia que tenemos del mismo. Gordon Matta-Clarck con otros artistas formaron el movimiento Anarchitectura como un espacio de discusión acerca de alternativas conceptuales a la arquitectura, al 'vocabulario establecido' de esta práctica, el origen y el significado de la arquitectura. Los Anarquitectos pretendían investigar y dar visibilidad, a través de la representación de un mundo mediada por una intención gráfica, a lo oculto, lo invisible o lo censurado, sea a través de un corte, una extracción o una composición abstracta. 


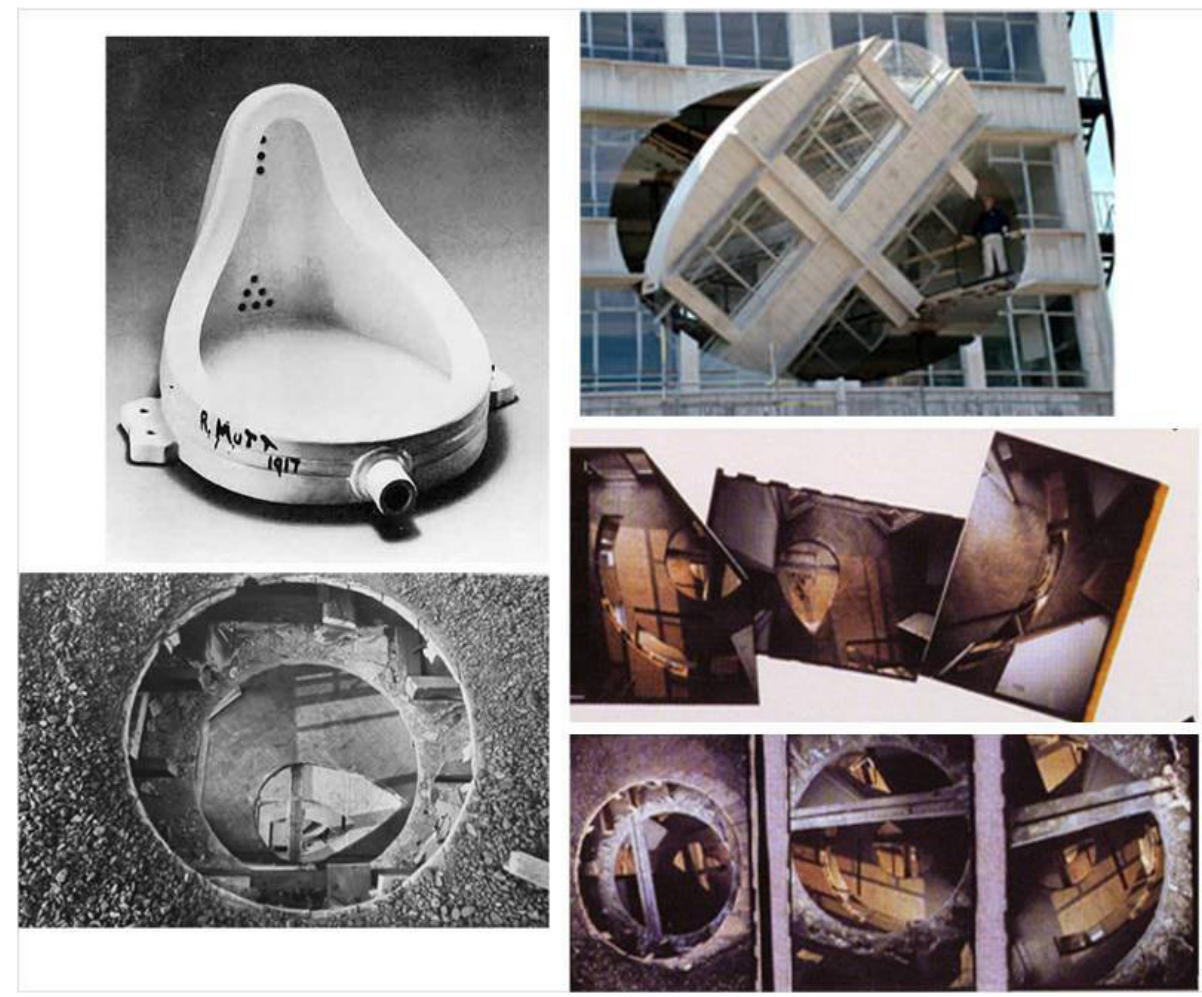

Figura 1. El famoso urinario de Duchamp junto con fotografías de Gordon Matta-Clarck de edificios perforados.

Si hoy la imagen, la red y la experiencia virtual se imponen en nuestro conocimiento del espacio-mundo, la fotografía y el cine anticiparon esta situación. De películas como "Berlín, sinfonía de una ciudad" (1927) de Walter Ruttmann, "El hombre con la cámara" (1929) de Dziga Vertov, o "Lluvia" (1929) de Joris Ivens, que describen el ritmo ordinario de la ciudad en movimiento, se desprende una nueva manera de "ver" que busca reconstruir una percepción dinámica y móvil del espacio constituyendo así un nuevo campo de reflexión sobre la ciudad.

Películas más contemporáneas de autores como Wenders o Tarkovsky nos ofrecen fragmentos auténticos de vidas y lugares comunes. En "Cielo sobre Berlin" (1987), la cámara de Wim Wenders observa a gente sencilla en sus actividades cotidianas, en sus recorridos diarios, en un intento de desvelar sus pensamientos ocultos, la angustia, los dilemas, las incertidumbres que pueblan paisajes urbanos también inciertos: la línea del muro, el descampado donde la carpa de un circo ha dejado su huella, las ruinas que evocan la destrucción bélica... La vida de la ciudad observada por "los ángeles", cerca de los seres humanos o en sus visiones de pájaro, se vuelven imágenes poéticas de la ciudad en blanco y negro (Fig.2A). 
El film del director ruso Andrei Tarkovsky, "Stalker" de 1979, trata de un cazador que lleva personas a explorar una zona prohibida. El lugar de la exploración, llamado "la zona", es descrito como impenetrable, impredecible y mutante en sus formas. Quién entra en "la zona" debe estar atento porque podría perderse y no volver. Finalmente el Stalker se revela como auténtico poeta que ha ideado en su mente la imagen de "la zona" que transmite a los otros exploradores que, en su desesperada búsqueda de emociones, han sido llevados a una zona que nada tiene de extraño sino en el imaginario de sus protagonistas. En este film se pone en evidencia la potencialidad del condicionamiento dado por las situaciones construidas (Fig.2B).
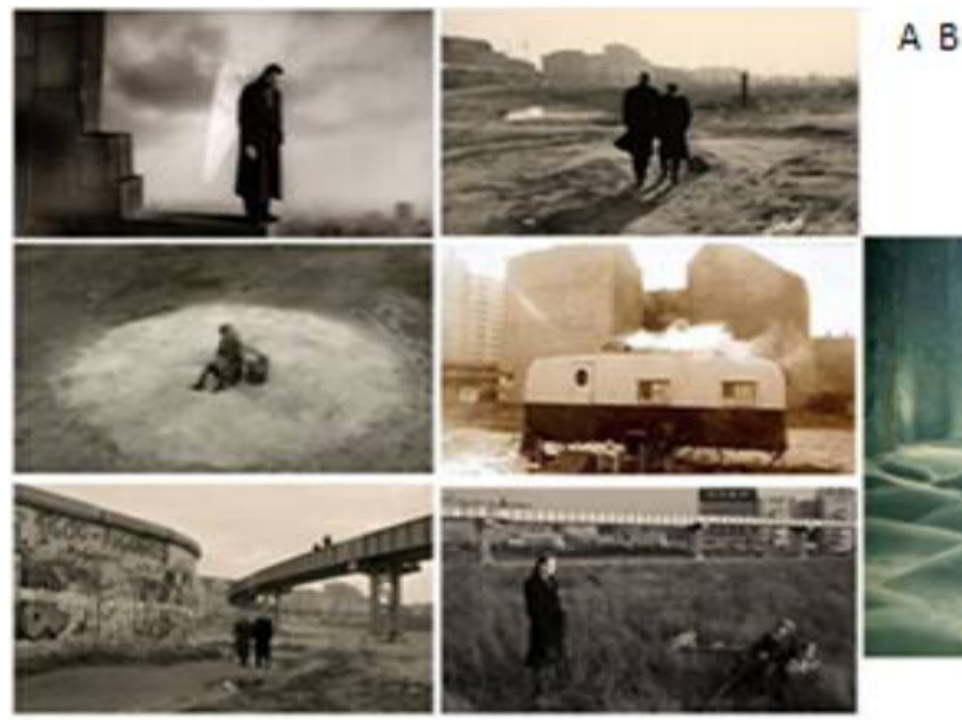

Figura 2. Fotogramas de las películas: A. "Cielo sobre Berlin" de Wim Wenders y B. "Stalker" de Andrei Tarkovsky

En ambas películas se evidencia la relación con una estética del "objeto encontrado", con la descontextualización o poetización del objeto común que guiará los pasos del arte plástico a partir de los sesenta buscando formas de romper los límites de la obra, de liberarla de la galería poniendo en crisis su elitismo y carácter comercial. Para ello, los artistas buscaron espacios naturales como soporte de las obras interviniendo en lugares a veces inaccesibles para los espectadores. Generaron así obras que cuestionaban los límites físicos y conceptuales de la obra, preguntándose desde y hasta qué punto una intervención humana puede ser una intervención artística y si una obra de intervención efímera, destinada a desaparecer por los efectos de la naturaleza, podía o no ser considerada arte.

Robert Smithson y Richard Long han intervenido sobre la naturaleza encontrada trabajando con sus materiales y las fuerzas telúricas marcando los comienzos del Land Art como intervención directa del artista sobre la realidad. Con obras como "Spiral Jetty" (Fig.3B), un espiral enorme construido por rocas de basalto, cristales 
de sal y barro en el Great Salt Lake en Utah o "A Line Made by Walking” (Fig.3A), trazada por los pasos humanos sobre la tierra, estos artistas pretendían integrar en la obra la noción de la temporalidad y la transitoriedad de tantas otras expresiones del territorio debidas a las actividades industriales, mineras y agrícolas (Fig.3A).

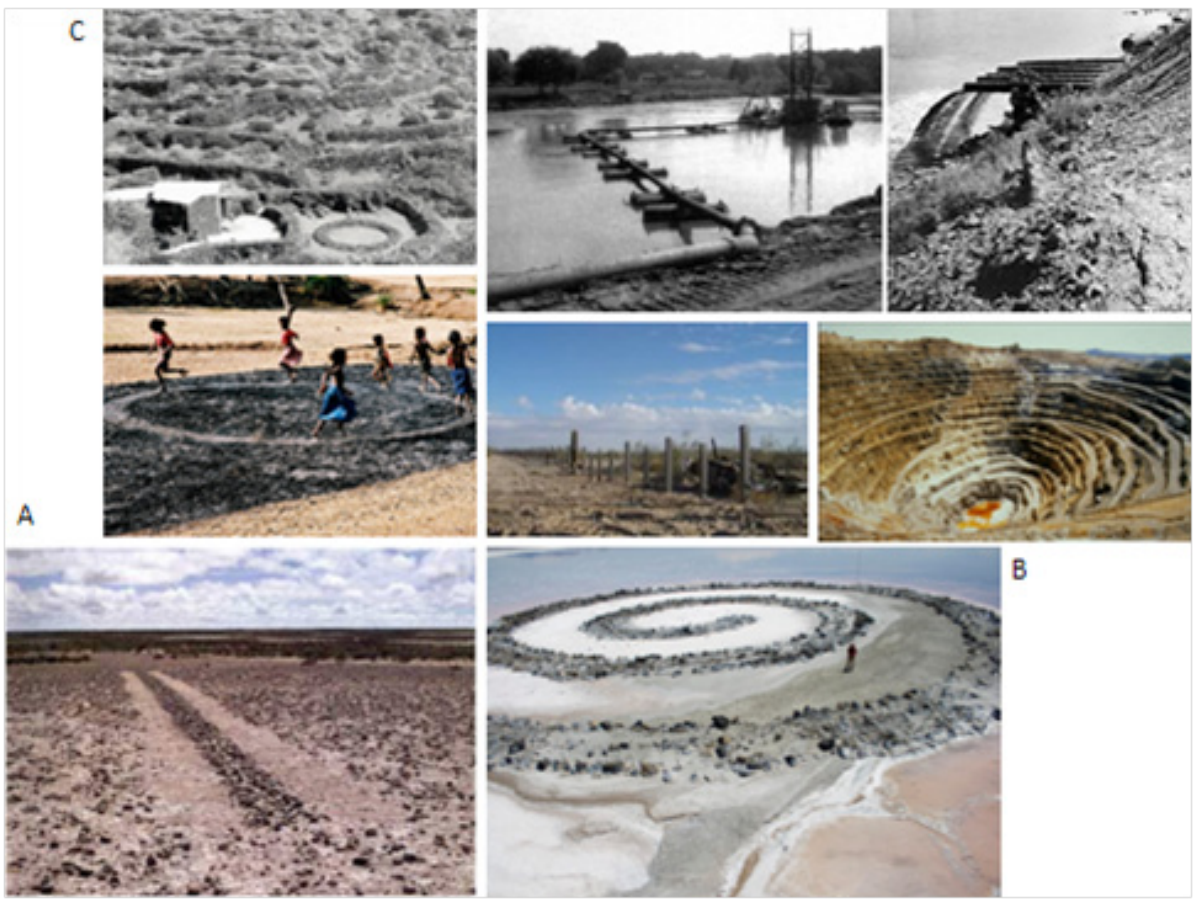

Figura 3. A."A Line Made by Walking” de R. Long, 1967; B. "Spiral Jetty" de R. Smithson, 1970; C. Otras expresiones del territorio debidas a las actividades industriales, mineras y agrícolas (fotografías procedentes de internet).

Jiannis Kounellis realiza un arte povera trabajando con materiales naturales o poco transformados en la que busca su relación profunda con el "lugar". Cuando le encargan una exposición, habitualmente no tiene ninguna obra para exponer. La obra no está preconcebida; se genera en el lugar de la exposición. Sus instalaciones usan el mismo espacio como soporte de la obra.

Los artistas del movimiento Fluxus como Beuys trabajan con el cuerpo y creen que el artista, debe actuar directamente sobre el mundo. El sistema de mediaciones del arte debe ser funcional a esa acción, y no al revés. El artista y la obra son una misma cosa. El artista se implica con su propio cuerpo en la obra que es una acción, una manifestación, una posición crítica frente a la realidad. A lo largo de la década de los setenta, la obra de Beuys se convirtió en discusiones públicas sobre libertad y democracia directa que produjo en distintas instituciones y museos y la más conocida de sus "esculturas" son los siete mil árboles plantados como parte de un proyecto para la Documenta de Kassel entre 1982 y 1987 (Fig.4). Lo que más importa es la 
participación, la interacción entre el artista, la obra y el público-actor o coautor. La funcionalidad inmediata de la obra. ¿Qué más funcional al disfrute de los sentidos que plantar 7000 árboles?
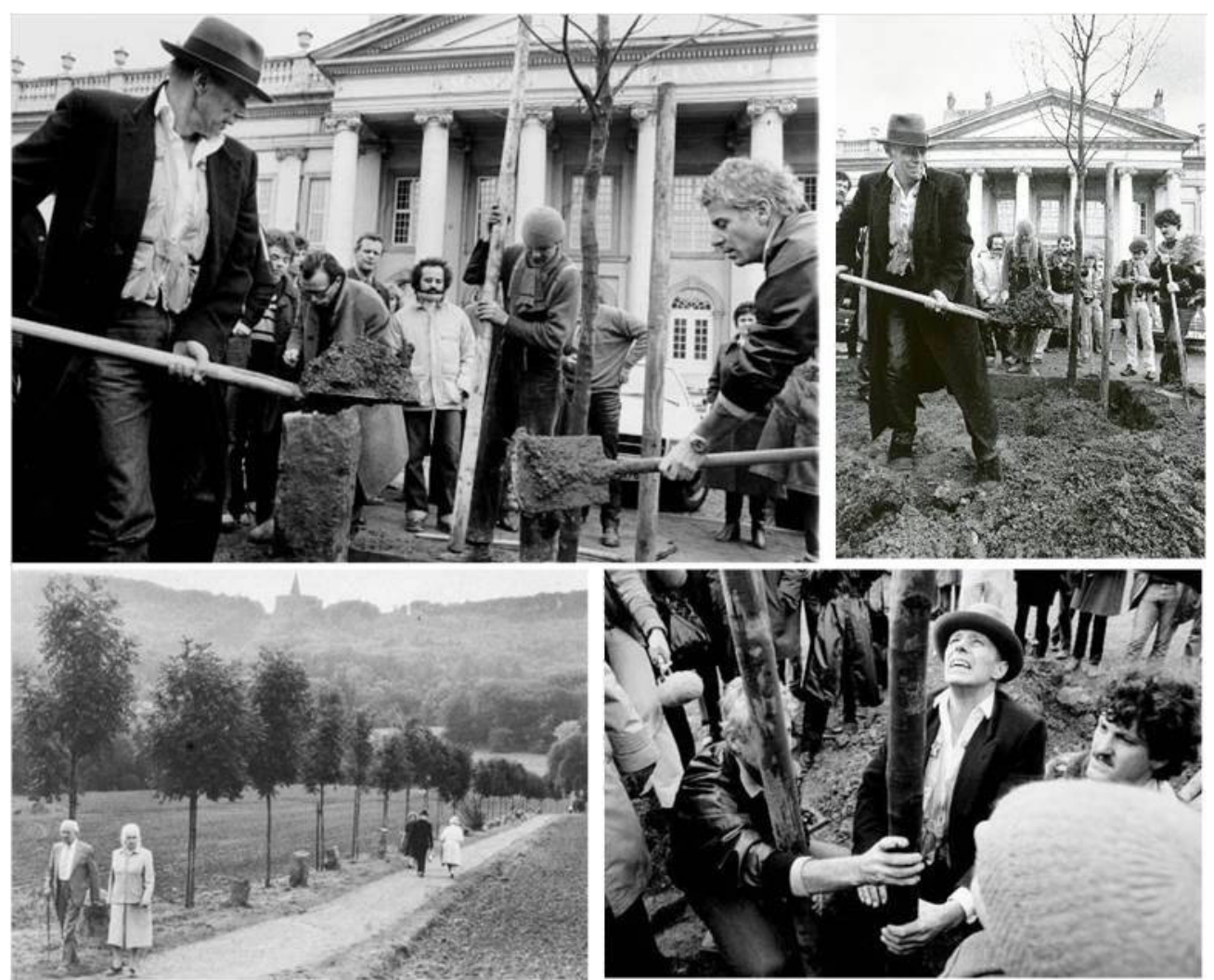

Figura 4. La plantación de árboles de Josef Beuys en la Documenta de Kassel (fotografías recuperadas de http://www.turbulence.org y http://pablogarabato.wordpress.com)

La fotografía jugó un papel fundamental en este tipo de arte efímero, de carácter conceptual, como medio de registro de las intervenciones artísticas volviendo paradójicamente a las galerías y los museos. No es casual que la fotografía escogiera entre diversos aspectos para retratar, aquellos desmarcados de los mitos centrales, de las imágenes dominantes. Como el arte de la representación naturalista por excelencia, ha sido prolífica en captar situaciones comunes y marginales como, por ejemplo, las ruinas industriales, que llenaron los textos y las paredes de las salas de exposición; atestiguando la modernidad caduca de aquel sueño de progreso y su fracaso. Construcciones anónimas y ambientes abandonados y degradados encontraron un lugar en la fotografía. El arte mostrando los escenarios del pasado reciente desde el punto de vista formal sin ningún matiz de tipo de reivindicación política, ideológica, y ni siquiera sentimental, es el caso de las fotografías de los Becher y otros 
profesionales. Sus fotografías retratan las periferias urbanas extrayendo de las zonas industriales abandonadas cualidades insólitas: fuerza y belleza. "Paradójicamente, la representación del mundo moderno-industrial se convierte ahora en símbolo del pasado, de su memoria" (Marrodán, 2007, 107). Algo feo y grotesco puede ser conmovedor porque la atención del fotógrafo lo ha dignificado. Aunque tradicionalmente la crítica ha juzgado la contemplación romántica de la ruina desde un supuesto gusto por lo anacrónico, el artista contemporáneo pone en crisis el afán humano creador y a través de la contemplación de esos espacios devastados y abandonados se enfrenta a sí mismo, a sus límites. En un momento como el actual, en el que el ritmo que marca la sociedad apenas deja tiempo para pararse y pensar, esos espacios adquieren un valor positivo frente al exceso de espacios "llenados" de contenido.

El paisajista Peter Latz se enfrenta a las ruinas industriales incorporándolas en un nuevo paisajismo. Su modo de actuar absolutamente contemporáneo, es el del hombre que mira con objetividad esas ruinas. Como elementos ajenos a una historia, trata de configurar un nuevo entorno donde las sensaciones espaciales y los valores formales que resultan del espectáculo de la desindustrialización, se convierten en los elementos del proyecto nuevo. Se trata que las personas mantengan un contacto corpóreo con la obra mientras se desplazan a través de ella, la usan y disfrutan de los ambientes creados. Landschaftspark Duisburg-Nord (1991-2001) es una intervención de Peter Latz sobre las antiguas acerías de la compañía Thyssen donde en lugar de construir objetos para usos específicos deja que la fantasía y la diversión hagan posible que las construcciones existentes funcionen como construcciones abstractas de una manera completamente nueva (Fig.5A). "El viejo alto horno aparece ahora como un dragón amenazante y es también una montaña para escaladores mientras que los antiguos depósitos de mena se convierten en jardines. Un club de buceo utiliza los viejos depósitos Möller y el antiguo gasómetro para buscar aventuras subacuáticas" (Latz, 1999, 207). 


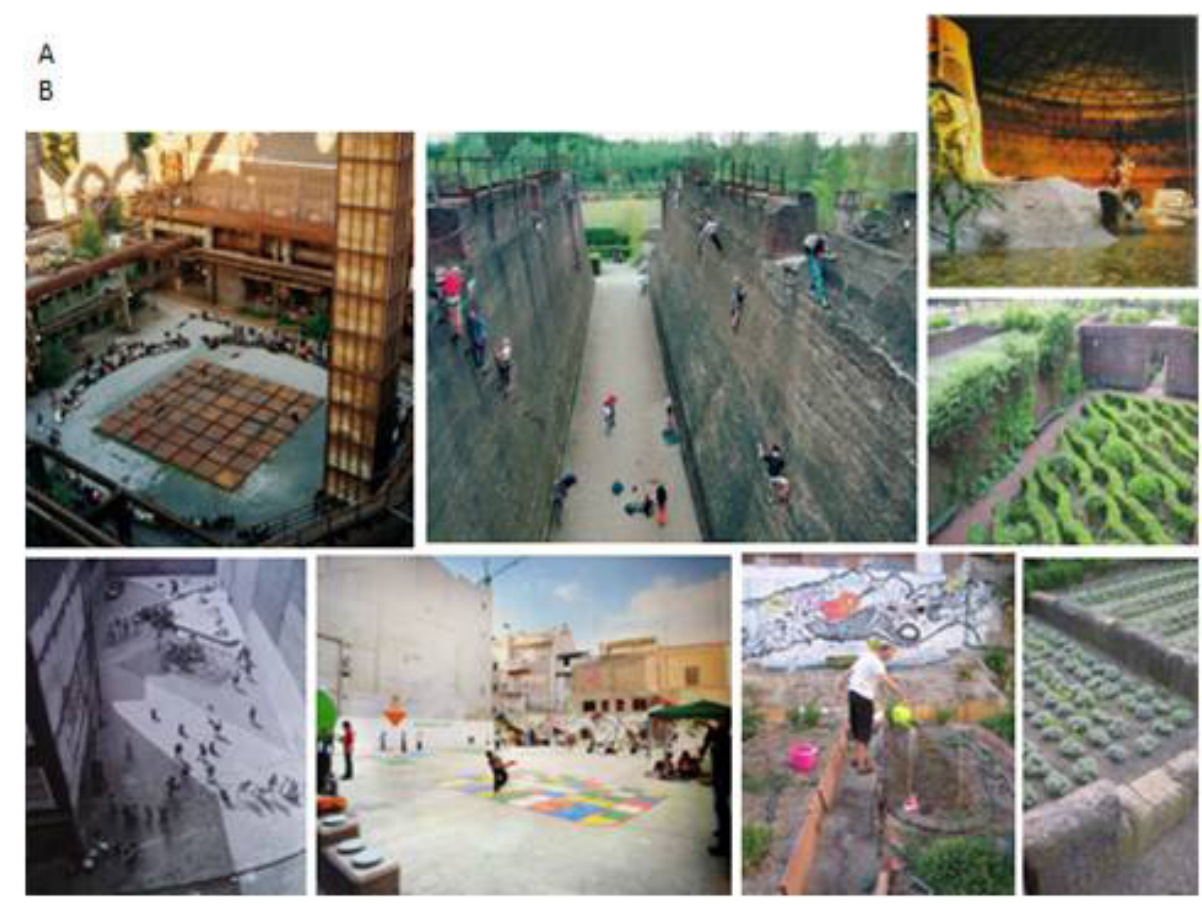

Figura 5. A. Landschaftspark Duisburg-Nord de Peter Latz y B. Intervenciones informales en solares vacios (imágenes disponibles libremente en diferentes web)

Los nuevos parques en la cuenca de Ruhr que han surgido tras la desindustrialización están compaginando esta concepción con la restauración ecológica del territorio, con nuevos usos recreativos, culturales y empresariales. Una nueva y diferente manera creativa de reciclar y aprovechar las áreas industriales obsoletas para nuevos usos, predominantemente culturales, se incorpora en estrategias ambientales regionales. En ellas se concilian planes de conservación del patrimonio industrial, un funcionalismo dotacional y la implantación de vegetación en consonancia con un naturalismo estratégico. Esta es una contemplación y una valoración distinta del espíritu funcionalista y del racionalismo europeo moderno que deja fuera la experiencia directa del cuerpo. Mediante esa experiencia, el ser humano puede imaginar y proyectar su propia vida en el futuro desde los ecos de un pasado que se agota. 'Quizá el nuevo 'culto' de las ruinas del pasado no es sino fenómeno de una época carente de ideales heroicos. Quizá la historia se repite, y al igual que en los primeros años de la industrialización personajes como Ruskin reaccionaron contra la mecanización, otros traten ahora de ponerse a salvo de la tecnología incierta" (Argullol, 2000, 30).

Esta nueva sensibilidad que valora lo común -incluso lo obsoleto y degradadocomo una nueva construcción intelectual, está dando paso a una reflexión sobre la experiencia espacial. La obra y su representación, la acción y la ficción, la realidad 
y el arte, la experiencia directa del cuerpo y la experiencia mediada, son elementosparte de la misma problemática de una redefinición del los límites del espacio. En performances, instalaciones $y$ transformaciones creativas de lo existente, activismo ciudadano e interacción en la red, en los diferentes registros de la realidad y sus manipulaciones, se ponen en cuestión los límites entre el espacio físico y el espacio percibido, sentido, intuido o inducido.

Según León Florido $(1998,22)$ es en la cuestión del límite donde radica la diferencia entre la ciudad tradicional -la polis- y la ciudad híbrida que se puede denominar "metápolis". La polis sigue ofreciendo el modelo de lo que significan los límites en relación a las posibilidades de convivencia de los habitantes de la ciudad, que vienen a ser el elemento material imprescindible para construir una barrera que pudiera oponerse al permanente fluir del tráfico de información en que han derivado las actuales megalópolis, fenómeno tras el cual se esconde la causa principal de la desaparición del ámbito público en las ciudades actuales. Es esta misma utopía del espacio indiferenciado cuya única función es presentar una vaciedad libre para dejar transitar los flujos de información, la que se encuentra en la base de la célebre afirmación de Robert Venturi según la cual los norteamericanos no necesitaban plazas para el encuentro estando cómodamente en sus casas viendo la televisión.

La ambigüedad de los límites del espacio hasta su desaparición se hace patente mientras se acorta la distancia que existe entre recorrer un lugar directamente y recorrerlo virtualmente. La conciencia de los límites entre espacio íntimo y espacio público se diluye mientras se ensayan formas de reproducir imágenes lo más fieles posibles a las sensaciones corporales y perceptivas que esos espacios pueden suscitar. La verdad es, como afirma Susan Sontag (1996), que tenemos la experiencia del mundo, cada vez más, a través de sus imágenes. La integración de las herramientas de comunicación visual en la red, como Youtube, GoogleMaps y GoogleEarth nos permiten acceder a la visión de todo el mundo como una gran superficie navegable y visible desde el vuelo de pájaro o de satélite. Los sitios de Flickr, Facebook, Fotolog, etc. extienden la proliferación de instantáneas y videos de lugares visitados o habitados por la gente del mundo. La herramienta complementaria de GoogleMaps, Streetview permite recorrer ciudades como París, Madrid y Nueva York de manera virtual en un espacio conformado por una sucesión de fotografías panorámicas, ensambladas para dar la sensación de un recorrido verdadero por todas las calles de estas grandes capitales. Es la lógica de lo que Baudrillard $(2002,187)$ denomina experiencia del mundo a través de "una pantalla y una red [...], una superficie no reflexiva, una superficie inmanente donde se despliegan las operaciones, la suave superficie operativa de las comunicaciones".

Parafraseando a Mallarmé, cuando decía: en el mundo "todo existe para culminar en un libro" o a Susan Sostang $(2006,44)$, "todo existe para culminar en una fotografía", todo, finalmente, culmina en la red. Ya no se puede desvincular la construcción de la ciudad de esta experiencia espacial vital a través de la pantalla. Continuamente observamos como los ciudadanos fotografían, graban y difunden videos, narran lo ocurrido, lo que está ocurriendo, siguen y transmiten, a través de twitter y facebook, informaciones a tiempo real. Los arquitectos así como varios artistas están indagando en estas cuestiones y bien supieron proponer obras, espacios y lugares propiamente 
de naturaleza híbrida optimizando la capacidad de los medios para la participación de los individuos en procesos creativos que se desarrollan en la red y tienen un efecto in situ.

El grupo Ecosistema urbano, por ejemplo, idearon y realizaron Dreamhamar, un proyecto para la transformación de una plaza popular de la localidad noruega de Hamar con aportaciones de ideas de los ciudadanos en la red, que después ellos mismos llevaron a la práctica. Están también las intervenciones informales de autoconstrucción de espacios lúdicos y para la socialización, transformaciones urbanas capaces de asumir usos temporales como las muy difundidas huertas urbanas, la ocupación y gestión creativa de solares, espacios residuales y edificios sin uso y un largo etc. de situaciones que se crean fuera de los canales convencionales (Fig.5B). Están también las "prácticas de disentimiento referidas a las ocupaciones temporales ideadas desde el ingenio, el reciclaje y la acción parasitaria, la "a-legalidad" en la que se mueven, las prácticas de supervivencia y de la marginalidad con sus mecanismos flexibles para permanecer en la ciudad; la ciudad entendida también dentro de una economía crítica obligada a desarrollar nuevos mecanismos de configuración espacial a través del reciclaje, la inclusión de espacios residuales, etc." (Trachana, A. 2012b: 425). Todos ellos son espacios poco conformados, efímeros o improvisados que surgen en precario desde las bases de la ciudanía como reivindicación de espacio vital. La mayoría de estos fenómenos contemporáneos, como resistencia también al capitalismo y al consumismo, la insostenibilidad del desarrollismo urbano y la destrucción del medio ambiente, así como manifestación de una contracultura, no serían posibles sin internet, redes sociales y dispositivos móviles y fijos para conectarse, convocarse, comunicarse, colaborar, darse a conocer y, finalmente, legitimarse. Esta parte informal de la ciudad termina adquiriendo una identidad y una legitimidad por estar en la red.

Muchas iniciativas marginales han ido derivando hacia nuevos paradigmas de urbanismo como, por ejemplo, el reciclaje de los contendores de barco como formas de alojamientos reversibles, muy flexibles, y de un coste sostenible; la promoción por parte de los propias administraciones del reaprovechamiento de espacios, solares y edificios vacíos, abandonados y obsoletos, para usos sociales y culturales y un largo etc. de nuevos paradigmas que tiene una identidad digital y física a la vez, se dan en todas las ciudades hoy bajo distintas fórmulas de participación ciudadana e instituciones conjuntamente. Un urbanismo blando, alternativo y participativo donde los vecinos colaboran con los profesionales y las administraciones públicas en la toma de decisiones y para dar soluciones no convencionales a problemas y necesidades comunes está rescatando, podemos decir, los valores positivos de la parte informal de la ciudad. Hay una constante retroalimentación entre procesos espontáneos y actuaciones lideradas por profesionales, de modo que los papeles entre arquitecto y usuario van confluyendo. Todas ellas son posibles gracias a las herramientas que facilitan la comunicación, la participación y la interacción (Trachana, 2013b, 106).

Esta nueva tendencia de ciudanía proactiva tiene como referentes, las diferentes manifestaciones artísticas a partir de los sesenta, algunas de las cuales hemos querido revisar muy someramente. Pero de crucial importancia e inspirador de las mismas fue el Movimiento Situacionista cuyos principios encontraron un eco en los princi- 
pios deconstructivistas de Jacques Derridá dando lugar a un derrumbamiento de la representación del espacio cartesiano, al espacio arquitectónico de la perspectiva, lo que para Carlos Jimenez $(2000,137)$ es una propuesta asimismo de "la desintegración del sujeto cartesiano": la desestructuración del punto de vista único que será abordada de diversas maneras, a fin de entender y reproducir la experiencia dinámica y desestabilizante del espacio. Eso es, concebir el espacio como movimiento, acción y comunicación. En otros términos, su representación podría asemejarse más a un collage fotográfico de encuadres múltiples y singulares como los que hace Gordon Matta-Clark para retratar sus trabajos escultóricos de edificios perforados, con sus encuadres singulares de extracciones de muros y agujeros, etc. (Fig.1).

Puede decirse entonces que una nueva manera de ver el espacio según estas referencias del campo del arte y la filosofía -la deconstrucciíón y Derridá-, visión que interesa también a la práctica arquitectónica y el urbanismo, es justamente la que logra expandir el campo de la representación espacial, expansión que es homologable a aquella que logra ampliar las posibilidades de percepción a través de mecanismos que son expansivos pero al mismo tiempo deconstructivos. Si para las artes de la representación naturalista, es la deconstrucción del punto de vista fijo, entronizado e incorpóreo de la perspectiva cartesiana, a partir de los nuevos recursos tecnológicos de mediación en la experiencia espacial, se roturan profundamente tácticas deconstructivas de los límites del espacio homologables a una experiencia de la realidad ampliada, percibida como intensas dinámicas de intercambios, interacción, cambios y roturas. En ellos tiene lugar una dialéctica entre el orden y el desorden, se encuentran las referencias para una convivencia de las diferencias. Frente a un universo de lo formal-legal dominado por la nitidez y la rigidez de la geometría aquí reside una sabiduría y una nitidez ética que posibilita mezclar las cosas e integrarlas. Aquí emerge la propia esencia creativa de los individuos. El espacio urbano no es un mero recipiente de la acción de los ciudadanos sino un espacio que se genera actuando. Aprendemos a observar los comportamientos y las actitudes humanas, las experiencias individuales y colectivas, las nuevas formas de sociabilidad, la invención de nuevos lenguajes, las distintas formas de atribuir valor y sentido al espacio urbano más que las formas solidificadas de la edificación.

Según Stavridis, (2003), si la ciudad moderna podría asimilarse a una pantalla donde la experiencia del espacio se atrapa con la percepción de su imagen y la vida social se representa como una serie de instantáneas sin continuidad y coherencia, como una serie de planos fuera de lugar y tiempo, se están explorando hoy todas las posibilidades de liberarse de este encanto de las imágenes modernas y de la experiencia del espacio que procesan. Sí los iconos modernos reducen la experiencia espacial de la acción humana, reduciendo así la vida en su escenificación, congelando el tiempo, podríamos hablar hoy de una performatividad o teatralidad que constituye en sí misma una experiencia del espacio basada en la gestión del tiempo. Esta performatividad o comportamiento teatral se despliega hacia fuera, permite salir hacia la alteridad, puede acercarse a ella y retornar; permite probar, trata de influir y ser influida. Por lo tanto, se puede definir como un campo de la negociación. Las imágenes fijas trataban hacer que prevalezca el presente sobre el pasado y determinar el futuro esencialmente a través de su influencia normativa. Era la teatralidad de los fuertes 
que intentaba atrapar la vida social en una condición que confirma las identidades, los roles, y por lo tanto, los limites. Nos trae a la mente la escena trágica de Serlio, mientras que su escena cómica respondería a la teatralidad de los plebeyos. Ésta emerge a partir de las tradiciones burlescas e iconoclastas, puede, sin embargo, ser desmitificadora y distanciadora. Puede, por lo tanto, indicar en el seno de lo mismo, lo existente, la aparición de lo otro, de lo nuevo y de lo utópico. En lugar de límites, la performatividad "de la negociación" configura lugares y tiempos intermedios, habita en los umbrales; erige en las entrañas de una ciudad pantalla fragmentos de una ciudad escena, una ciudad de umbrales, de heterotopías, experiencias colectivas, convivencia característica en sus contradicciones, en sus problemáticas pero también en su capacidad emancipadora que propicia la solidaridad más que la asimilación.

\section{Tecnología y ciudadanía proactiva}

Gracias a los dispositivos tecnológicos y las redes sociales virtuales se posibilitan nuevos modos de experimentar la ciudad en un encuentro lúdico entre el espacio físico y el espacio virtual. La mediación de la experiencia de la ciudad se produce, nos dice Barthes (1995), por un lado como un registro de una realidad objetiva y dada donde las imágenes son referenciales, una "huella" de la realidad y por otro, como una manipulación de la realidad o creación de una realidad nueva en lo que "toca" subjetivamente y se refleja como una deconstrucción de la realidad objetiva: sensación de movimiento, dinamismo, complicados puntos de vista, dificultad de determinar las coordenadas espaciales, imágenes dramáticas y atmosféricas... ¿Hasta qué punto esta experiencia espacial puede ser representada? Es una cuestión que nos enfrenta con la problemática del acto comunicativo y su referente más que de la representación mimética o de la realidad representada.

En los noventa comenzó a llamarse "hipertexto" e "hipermedia" un modo de entender la ciudad como una ficción, un gran espacio donde se desarrolla nuestra ficción. Y este gran espacio de ficción que es la ciudad contemporánea afecta, por supuesto, a las personas que lo habitan y a la forma en que lo hacen. Si hasta hace poco esta ficción, esta forma de construir la realidad de las ciudades era una tarea básicamente arquitectónica y urbanística, desde ya hace unas décadas, como ya hemos visto, nuestra forma de entender la ciudad se ha alterado bajo la influencia de las tecnologías de la comunicación. Hoy, una ciudad tiene otra dimensión: es un paisaje de información, un "infoscape" variable cuyos contenidos afectan directamente a la forma de percibir y vivir la ciudad. Los diferentes sistemas y dispositivos de acceder a la información, fijos o móviles, personales o públicos, desde los grandes sistemas visuales de información exterior -los muros pantalla o el digital signage- hasta los dispositivos móviles personales, desde el aislamiento personal hasta la sobreinformación a través de los sistemas de realidad aumentada, los códigos QR o la información automática geoposicionada, alteran de forma absoluta la percepción de nuestro entorno; posibilitan nuevas formas de construir nuestra realidad. Por eso, aceptamos el "juego" de entender la ciudad como "un escenario de ficción", "un escenario de 
ficción total" como punto de partida que nos ayude a reflexionar y afrontar la nueva situación urbana.

Hoy, como dice M. Delgado (2007), hay que entender lo "urbano", como una "masa movediza", "sociedad líquida" (Bauman, 2007) e "invisible" (Innerarity, 2004) que reivindica el uso de la tecnología como instrumento de colaboración y mediador de la realidad pues, nos comunica, nos globaliza y nos convierte en una comunidad distinta. En un mundo cada vez más inconexo físicamente pero conectado tecnológicamente -virtualmente-, la tecnología está contribuyendo a "reinventar lo común de los hombres" (Negri, 2010) y a concebir una nueva forma de "estar juntos" (Maffesoli, 1990). Esa es una de las grandes gestas que nuestra época -a la vez globalizada y ultralocal.

Forma parte de la rutina cotidiana de cualquier individuo, recibir y editar información, interactuar en tiempo real con otras personas, participar en debates, movimientos sociales y en la organización de cualquier acción. Gracias a las redes sociales y múltiples herramientas interactivas, se está construyendo hoy una esfera comunitaria y pública completamente nueva que altera la conducta del ciudadano frente al espacio público, lo que se traduce a un modo más sensible, más consciente, más solidario y más responsable de actuar y relacionarse con los demás. También hace que se presenten objeciones teóricas contra los modelos dominantes de "espacio público", y el concepto de "lugar", asociados a la ciudad estable y su mitología.

Podríamos hablar de una "ciudad hibrida" tecnológicamente "conectada" y potencialmente "abierta" a la participación de todos. En esta se estimula la creatividad ciudadana y la capacidad de los profesionales para acometer iniciativas y liderar proyectos no convencionales que emergen desde "abajo"; iniciativas fuera de las predeterminaciones de los planes, planes que ya no lideran sólo las instituciones públicas sino los ciudadanos asesorados por profesionales que utilizan las nuevas herramientas en el desarrollo de procesos interactivos. Estas herramientas se constituyen en herramientas educativas del ciudadano, que está protagonizando un nuevo proceso de aprendizaje, una movilización de todos sus sentidos, no sólo la vista. Eso es cinestesia, en vez de continuar haciendo lo mismo de siempre, movilización; empieza a actuar de forma diferente, a generar nuevas ideas y desvelar nuevos significados; empieza a ser creativo, a emprender nuevas aventuras que le proporcionan placer; aprende a captar la realidad con una mirada diferente, motivadora y así se inician procesos creativos con acciones decisivas de transformarla. En este proceso, los descubrimientos de aspectos ocultos y desconocidos de la realidad terminan por expresarse al exterior con la facilidad e inmediatez de los medios que tiene a su alcance. Se generan así nuevas experiencias, nuevos hábitos y aumenta la capacidad de innovar los mecanismos productivos del espacio de la ciudad.

Esa innovación se basa fundamentalmente en la creación de vida social y de cultura política. Hoy se reconoce valor no sólo en la transacción económica y está creciendo el paradigma de lo "procomún" inaugurando un debate humanista más amplio que renueva las conexiones entre los valores democráticos, la vida social y los espacios públicos. Los espacios públicos se entienden como espacios lúdicos, espacios para la creatividad y la innovación de los usuarios no sujetos a un orden simbólico pre-establecido, lo que comporta la libertad de la expresión y la participación, el 
ejercicio de la ciudadanía. Son espacios dinamizadores del devenir de la cotidianidad. Los elementos que conforman estos espacios expresan a veces el mundo de ideas, discursos, y utopías de la ciudad. Pero no se puede reducir su significado al trazado, diseño, construcción arquitectónica y formas de ocupación y uso previstos en su proyecto. Fundamentalmente, esos dependen de la interpretación y muchas veces de una refundación y el uso espontáneo que se les dé. Espacios de nueva generación, casi siempre en las fronteras entre la necesidad y la creatividad de sus "usuarios", se crean a partir del momento que personas actúan conjuntamente. La mayoría de las veces, son ajenos a las políticas culturales, es más, actúan en sustitución de ellas y por la carencia de ellas (Trachana, 2012b, 425).

Los múltiples recursos tecnológicos que disponemos, la utilización de blogs, wikis, redes sociales y, de máximo interés hoy, la utilización de internet en dispositivos móviles -que sirve para realizar un seguimiento automatizado de las fuentes de información- contribuyen, sin duda, en el aumento de la creatividad ciudadana. El binomio tecnología y creatividad se ha demostrado tanto en el mundo académico como en los diferentes sectores de la producción. Las actividades desarrolladas gracias a las nuevas herramientas permiten dar respuestas a diferentes problemas con tecnología y además aprender sobre cultura, sobre el ser humano y todo tipo de conocimiento se hace más accesible. Estamos, sin duda, ante una revolución social basada en la interoperatividad, en proyectos y estrategias centrados en el usuario y por los usuarios a través de internet y de las diferentes aplicaciones web. Estas herramientas que, generalmente son disponibles de forma gratuita, facilitan compartir información, permiten la participación y la colaboración en proyectos así como el emprendimiento de iniciativas.

Las instituciones locales explotando el potencial de los medios tecnológicos también empiezan a promover iniciativas para incrementar la participación del ciudadano en la vida artística y social de su ciudad que bordean los límites de la, hasta ahora prioritaria, profesionalización del sector cultural con el amateurismo que se constituye en alternativa y proceso complementario. Las 'Noches en blanco' madrileñas o 'Noches Eufóricas' de la ciudad francesa de Tournefeuille, por ejemplo, son proyectos que concilian políticas culturales y el apoyo a la creación, el vínculo entre el arte y la ciudanía involucrando la participación ciudadana en una transformación efímera del espacio urbano. Estas noches, la gente se reúne en torno a un acontecimiento a escala de la ciudad donde ellos son los actores y espectadores a la vez, en un entorno que combina equipamientos públicos y un entorno tecnológico-artístico avanzado. Con estos proyectos se pretende fomentar la creación artística y el desarrollo cultural urbano a través de "intersecciones" de tecnología y espacio público.

La tecnología digital, por otro lado, se adopta para abrir cauces de información recíproca entre ciudadanos e instituciones, aunque todavía estas plataformas funcionan en precario de forma bilateral, pero sí para disponer abiertamente información, homogeneizar datos de distintas plataformas, para coordinar servicios telemáticamente, y ofrecer facilidades y ahorro de tiempo, energía, etc. a los ciudadanos. Hay un amplio abanico de iniciativas públicas y privadas, locales, nacionales y a nivel europeo (para ampliar información véase Trachana, 2013a: 45-46). Queda sin embargo, mucho trabajo por hacer para desarrollar el potencial de las TIC en la transformación 
de la ciudad. Se habla hoy de la "ciudad de código abierto" -término que alude el acceso libre a la información urbana que las administraciones públicas disponen a los ciudadanos- y de la "ciudad inteligente" o smart city -que a través de las tecnologías digitales ofrece una diversidad de servicios avanzados- relacionados con el alumbrado público, el trafico, la contaminación, los residuos, etc. Pero la verdad es que la transformación de la realidad urbana está en manos de los ciudadanos y no en la tecnología en sí como producto y como tal, mero consumible y objeto de negocio; a la medida que la creatividad ciudadana vaya encontrando nuevas soluciones a los nuevos y antiguos problemas de la ciudad, lo que es factible a partir de las posibilidades infinitas de elección que existen. Entendemos esa creatividad como la capacidad que tienen los ciudadanos como individuos para captar la realidad y transformarla, generando y expresando nuevas ideas. Según Florida (2009), a la medida que esta capacidad de los ciudadanos se convierta en un estilo de vida, se vislumbran posibilidades nuevas para crear y recrear su entorno vital, mejorando sus condiciones de habitabilidad y convivencia.

"Las tecnologías de la información y las comunicaciones están protagonizando en las dos últimas décadas un cambio radical que no se limita a la innovación tecnológica sino que acompañan profundas transformaciones socioeconómicas y culturales surgiendo un nuevo paradigma que podríamos identificar como cultura digital" (Freire, 2010, p.23). "La ciudad contemporánea no puede entenderse ya sin la tecnología y las prácticas y la cultura digital que genera. Y los modelos de gestión urbana no pueden permanecer al margen de estos cambios sociales" (Freire, 2010, p. 71). Podemos entonces hablar de una identidad híbrida, presencial y digital. Di Siena (2011) habla de "activación territorial desde la cultura digital". La configuración de espacios públicos como lugares donde se garantiza el libre intercambio de información y donde se promueve la transparencia de la gestión vuelve a dar a la sociedad un papel fundamental devolviendo a estos espacios la vitalidad que parecían haber perdido.

También es verdad que las propias ciudades propician que evolucionemos como ciudadanos y nos convirtamos en multireceptores activos y conscientes de serlo. La difusión de contenidos que tienen como soporte la propia ciudad -las paredes, las fachadas, las megapantallas, el arte urbano- todo lo que se produce y se difunde contagia y hace que se generen más iniciativas; que crezca el amateurismo artísticocultural vinculante a la acción creativa sobre el entorno inmediato. Cada ciudadano puede contagiar y contagiarse con nuevas ideas. En el siglo XXI, las ideas, el arte, la cultura ya no se exponen, se difunden. La evolución del ciudadano del siglo XXI no es lineal, como plantea la educación formal; es orgánica y evoluciona a partir de las respuestas que obtiene del entorno. La posibilidad de satisfacer la necesidad vital de expresarse de forma inmediata, ejercita de manera incremental la imaginación y dota los sentidos de un poder inusual. El cerebro acepta y reacciona de manera automática ante la inmensa información que recibe en forma de palabras, imágenes, sonidos o sentimientos. La mente prácticamente no puede distinguir la diferencia entre una experiencia real y otra imaginada. El ciudadano se acerca, cada vez, con más confianza, libertad y apertura a este entorno facilitador para la expresión libre de las ideas. Jung decía: «El hombre cree que él moldea esas ideas, pero en realidad, son ellas las que lo moldean y lo hacen su intérprete inconsciente» 
Concluimos así con los nuevos "aprendizajes" de "hacer ciudad" como un "arte" que sobrepasa los instrumentos que hasta ahora nos hemos servido y nos sitúan en una encrucijada de la poiética como actividad ritualizable con potencia para deshacer las convenciones y como incentivo para fundar nuevos hábitos culturales y para la exploración de nuevas propuestas. La ciudad adquiere infinitos matices como proceso sostenible en la experiencia primaria y la ejecución constante que funda hábitos y reclama reflexión verbal y compromisos de vida. La ciudad practicada frente a la ciudad concebida, las acciones directas sobre lo preexistente y a través de la red constituyen este espacio híbrido -entre la "realidad" y la red- de la vida cotidiana que podemos cada día reinventar. Las nuevas tecnologías constituyen un medio para desarrollar nuevas dinámicas de comunicación y relación, capaces de mejorar la cohesión de las colectividades locales. Internet parece ofrecer un "lugar" para las relaciones sociales alternativo a los lugares "tradicionales". Este hecho que se podría entender como un problema causante del incremento sucesivo del vaciamiento del espacio público, puede considerarse por lo contrario, como una extraordinaria oportunidad para fortalecer las relaciones sociales locales.

Los nuevos modelos de gestión de la ciudad que se están experimentando hoy se generan en la red y se desarrollan in situ. Las nuevas dinámicas de comunicación y relación, capaces de mejorar la cohesión de las colectividades locales, se desarrollan en internet. Las relaciones digitales llaman las relaciones presenciales y en la red se genera la perspectiva de colectividad que tiene un reflujo en acciones y transformaciones físicas de un "lugar". La identidad híbrida, presencial y digital, es un hecho, un género nuevo de espacio que integra el potencial imaginario y virtual que propicia la tecnología digital en el espacio físico. Son espacios donde se generan dinámicas interactivas e intercambios de información, corrientes de empatía, solidaridad y convivencia. Es también una organización singular de la coexistencia basada en la carencia de "lugar", el "no lugar" y la "no ciudad". Estas nociones dependen de los valores perceptuales y sensibles que se les atribuye durante los desplazamientos, los cambios y la inestabilidad que constituyen su materia prima. El "lugar" sostiene Hannah Arendt (2002) sólo es" un lugar del espíritu", es un pensar y "para existir no se necesita de ningún lugar". El sujeto no está sino que trabaja, es el ser concebido como no-posición que por eso sólo puede ser dis-posición: apertura, expectativa ante lo que en cada momento está a punto de ocurrir.

Si la ciudad fue concebida como un todo organizado y cada ciudadano tenía una función propia a fin de que el conjunto funcione en armonía y sea auto-subsistente, como evidencia Platón en muchos lugares (por ejemplo, en Menon 72a), la polis constituida "naturalmente", era para los propios griegos una concepción de una naturaleza entre la naturaleza de lo físico y la naturaleza intelectual.

\section{Referencias}

Arendt, H. (2002). De la vida del espíritu. Barcelona: Paidós Ibérica.

Argullol, R. (2000). La atracción del abismo. Barcelona: Destino.

Barthes, R. (1995). La Cámara Lúcida: Nota sobre la fotografía. Barcelona: Paidós. 
Baudelaire, C. (1961). El pintor de la vida moderna (1 ${ }^{\mathrm{a}}$ ed.) México: Editorial Aguilar. [Ed. orig. 1863]

Baudrillard, J. (2002) "El éxtasis de la comunicación". En Foster, H. (Ed.). La Posmodernidad. Barcelona: Ed. Kairós.

Bauman, Z. (2007). Tiempos líquidos. Barcelona: Tusquets Editores.

Benjamín, W. (1998). El Paris del II Imperio en Baudelaire, La Bohemia, El Flaneur', Lo Moderno. Iluminaciones II, Madrid: Ediciones Taurus. [Ed. orig. 1938].

Buck-Morss, S. (1996). Dialéctica de la mirada. Benjamin y el proyecto de los Pasajes Madrid: Antonio Machado. La balsa de la medusa.

Crary, J. (1994). L'Art de l'Observateur. Vision et Modernité au XIXe siècle. Nîmes: Éditions Jacqueline Chambon.

Debord, G. (1957). Informe sobre la construcción de situaciones y sobre las condiciones de la organización y la acción de la tendencia situacionista internacional. Recuperado de Bifurcaciones 05 http://www.bifurcaciones.cl/005/reserva.htm

De Certeu, M. (1999). La invención de lo cotidiano. México: Universidad Iberoamericana.

Delgado, M. (2007). Sociedades movedizas. Barcelona: Anagrama.

Di Siena, Domenico (2011). Ciudades de Código Abierto. Hacia nuevos modelos de gobernanza local. Creatividad y Sociedad $\mathrm{n}^{\mathrm{O}}$ XVII, 10-17. Recuperado de http:// www.creatividadysociedad.com/articulos/17/ciudadesdecodigoabierto.pdf

Innerarity, D. (2004). La sociedad invisible. Madrid: Espasa Calpe.

Faucoult, M. (1997). Los espacios otros. Astrágalo Cultura de la arquitectura y la ciudad $\mathrm{n}^{\circ}$ 7, 83-91. [Conferencia dictada en el Cercledes études architecturals el 14 de marzo de 1967, y publicada (1984) Des espaces autres. Architecture, Mouvement, Continuité, $\mathrm{n}^{\mathrm{o}}$ 5. París].

Faucoult, M. (1998). Vigilar y Castigar. Nacimiento de la prisión. México D.F.: Editorial Siglo veintiuno editores.

Florida, R. (2009). Las ciudades creativas. Por qué donde vives puede ser la decisión más importante de tu vida. Barcelona: Paidós.

Freire, Juan y Gutiérrez Rubi, Antoni (2010). 2010-2020. 32 Tendencias de cambio. Recuperado de http://www.gutierrezrubi.es/wpcontent/ uploads/2010/09/32Tendencias_de_cambio.pdf.

Jimenez, C. (2000). Las Fotografias de Matta-Clark o las Exposiciones de lo Muerto". En Corbeira, D. (Ed.). Construir... o Deconstruir? Textos sobre Gordon MattaClark. Salamanca: Ediciones Universidad de Salamanca.

Latz, P. (1999). Los extraordinarios jardines posteriores a la era industrial. Actas Segundo Seminario Do.co.mo.mo. Ibérico. Arquitectura e Industria Modernas 1900-1965, 199-209. Sevilla: Junta de Andalucía.

Lefebvre, H. (1972). Espacio y política. Barcelona: Península.

Lefebvre, H. (1978). El Derecho a la ciudad. Barcelona: Península.

León Florido, F. (1998). Metápolis. La ciudad deconstruida. Astrágalo. Cultura de la arquitectura y la ciudad $\mathrm{N}^{\circ}$ 9, 17-42.

Maffesoli,_M. (1990). El tiempo de las tribus. El ocaso del individualismo en las sociedades posmodernas. Barcelona: Icaria. 
Marrodán, E. (2007). De la fascinación formal a la nostalgia. La ruina industrial en el paisaje contemporáneo. Revista Bienes Culturales. IPHE. Número 7, 103-118.

Negri, A. (2010). Inventer le commun des hommes. Paris: Bayard Éditions.

Nieuwenhuys, C. (1974). New Babylon (Manifiesto para el catálogo de una exposición en La Haya). Recuperado de http://www.notbored.org/new-babylon.html

Nicolas-Le Strat, P. (2006). Multiplicité interstitielle. Multitudes 31. Recuperado de http://www.le-commun.fr/index.php?page=multiplicite-interstitielle

Perniola, M. (2002). El arte y su sombra. Madrid: Ed. Cátedra.

Rendueles, C. y Useros, A. (2010). Walter Benjamin. Atlas-Constelaciones. Madrid: Círculo de Bellas Artes.

Ricoeur, P. (2000). Del texto a la acción. Ensayos de Hermeneutica II. Buenos Aires: Fondo Cultura Económica.

Sennett, R. (1997) Carne y piedra. El cuerpo y la ciudad en la civilización occidental. Madrid: Alianza.

Simmel, G. (1903) The Metropolis and Mental Life. Bridge, G. and Watson, S. Ed. The Blackwell City Reader. Oxford and Malden, MA: Wiley-Blackwell. Recuperado de http://www.esperdy.net/wp-content/uploads/2009/09/Simmel_21.pdf

Solá Morales, I. de (2002) Territorios. Gustavo Gili, Barcelona.

Sontag, S. (2006). Sobre la fotografía. Buenos Aires: Alfaguara.

Stavridis, S. (2003). De la ciudad pantalla a la ciudad escena [traducción del título del griego]. Athina: Ellinika Gramata.

Trachana, A. (2012a) Manual o digital. EGA (288-297). Valencia: DIGA.

Trachana, A. (2012b) Urbe Ludens. Ciudad y Territorio Vol. XLVI No 173, 423-444. Madrid: Ministerio de Fomento.

Trachana, A., Amann, A., Raposo J. Grigoriadou, M. Flores, J. (2013a) Citizens Interactive Behavior in the Performance of the Urban Space of Cohabitation. Interactive Atlas of Urban Habitability. Spaces and Flows: An International Journal of Urban and Extra Urban Studies, Volume 3, Issue 3, 41-58.

Champaign, Illinois, USA: Common Ground Publishing LLC.

Trachana, A. (2013b). "La ciudad sensible". Utrban NS05, 97-111. Madrid: DUOT 